\title{
The Authoritarian Predisposition and Liberal Beliefs about
}

\section{Democracy}

-Kris Dunn, School of Politics and International Studies, University of Leeds

Abstract: This research examines how variation in one's authoritarian predisposition is related to liberal beliefs about democracy. As a concept founded to explain the fall of Weimar Germany and the rise of authoritarian and fascist regimes post-WWI, individual-level authoritarianism is a prime suspect when considering the changing fortunes of liberal-democracy and democratic governance; a concern often expressed in recent literatures dealing with democracy-relevant attitudes and behaviors. While research on authoritarianism is usually focused on (in)tolerance toward outgroups, this article focuses on what people believe about democracy. Using data from the World Values Survey, among other sources, I look at how authoritarianism is related to liberal beliefs about democracy and how a country's democratic context influences this relationship. While hypotheses I derived from the literature propose that the more authoritarian will hold weaker beliefs that liberal characteristics are required for democracy and that this relationship will be stronger in more democratic countries, the data indicate the opposite: in less liberal-democratic countries, the more authoritarian more strongly believe that liberal characteristics are necessary for democracy; in more liberal-democratic countries this relationship diminishes to the point of insignificant. These findings are discussed in light of the current literature on authoritarianism.

Keywords: Authoritarian Predisposition; Liberal Democracy; Democracy Beliefs; Democracy Attitudes 
The original concept of an authoritarian personality arose from concern about antidemocratic impulses among democratic citizens (cf., Adorno, Frenkel-Brunswik, Levinson, \& Sanford, 1950; Fromm, 1941; Lipset, 1960); as an explanation for popular support for, or at least complacency toward, the rise of post-World War I fascist and totalitarian regimes. While the urgency to explain Fascist Italy, Nazi Germany, and Stalinist Russia, among others, has faded from the authoritarianism literature, the concern with anti- or un-democratic attitudes has not: both Altemeyer (1996) in the nineteen-nineties and Stenner (2005) in the two-thousands warn of the threat authoritarians pose to liberal-democratic governance.

Much of the concern in recent literature focuses on the intolerance and punitiveness frequently expressed by authoritarians toward outgroups. The principle concern being that intolerance in the electorate will find its way into office and thereafter into intolerant and punitive policy that may undermine liberal-democratic governance. While there is certainly reason for concern over how the presence and activity of authoritarians may impact governance, this paper takes a step back to examine a more fundamental question: given the recent change in how we conceptualize authoritarianism, do beliefs about democracy differ between authoritarians and their polar, libertarians?

Based on the common characterization of authoritarians as the enemies of liberaldemocracy and libertarians as its cheerleaders, there is certainly reason to expect a fairly large difference in how these ideal-groups think about democracy. The reflexive assumption would suggest that authoritarians hold illiberal beliefs about democracy while libertarians hold liberal beliefs about such. However, as pointed out by multiple scholars, the more authoritarian are more norm adherent than the average person. Authoritarians' beliefs about democracy may, then, be much more in line with the democratic norms of their society: in liberal-democracies, 
authoritarians may believe democracy to entail liberal characteristics, while in illiberal or nondemocracies, authoritarians may think of democracy as a more illiberal form of governance. Libertarians, on the other hand, are assumed to hold fairly liberal beliefs regardless of the political context, though one could reasonably assume that liberal beliefs about democracy among libertarians are stronger under liberal-democratic regimes as such beliefs are reinforced by the political context.

This article examines whether the evidence supports the general assumptions made above. In the first section of this article, I briefly present current theory on authoritarianism and the expectations regarding beliefs about democracy that arise from such. In the second section, I present the data - drawn from the $6^{\text {th }}$ wave of the World Values Survey $\left(\mathrm{WVS}_{6}\right)$, Freedom House's Freedom in the World country ratings (FIW), and the Worldwide Governance Indicators dataset (WGI) - and concept measurement that are used to test the hypotheses set out in the previous section. In the third section, I present the multi-level analyses of the data. Finally, in the fourth section, I conclude the article with a discussion of the relevance of the findings and how they fit into the broader literature.

\section{The Authoritarian Predisposition and Beliefs about Democracy}

How authoritarianism is conceptualized has changed considerably over time; transitioning from the psychoanalytic perspectives of Fromm (1941) and Adorno et al. (1950) through the social-learning perspective of Altemeyer (1996) to the values-based perspectives of Feldman and Stenner (Feldman, 2003; Feldman \& Stenner, 1997; Stenner, 2005) and Hetherington and colleagues (Hetherington \& Suhay, 2011; Hetherington \& Weiler, 2009). This article focuses on the latter conceptualization of authoritarianism. 
Feldman conceptualizes authoritarianism as a predisposition concerned with the appropriate balance between social conformity and individual autonomy (Feldman, 2003). This predisposition is anchored on one end by authoritarians, those who prioritize social conformity over individual autonomy, and on the other by libertarians, those who prioritize individual autonomy over social conformity. Importantly, and unlike previous conceptualizations of authoritarianism, this more recent conceptualization of authoritarianism is a predisposition to respond a certain way under certain conditions: authoritarians become notably more intolerant and punitive when the social unity and uniformity of their ingroup is perceived to be challenged or threatened (Feldman \& Stenner, 1997). When not threatened, the more authoritarian express similar levels of tolerance and forgiveness to the less authoritarian.

More recently, Hetherington and colleagues (Hetherington \& Suhay, 2011; Hetherington \& Weiler, 2009), though adhering to Feldman and Stenner's (Feldman, 2003; Feldman \& Stenner, 1997; Stenner, 2005) conceptualization of authoritarianism as a predisposition ${ }^{1}$, provide evidence in support of a thesis which is subtly but fundamentally different from that of Feldman and Stenner. Hetherington and colleagues seem to agree with Stenner that in the absence of any perceived threat, both the more and less authoritarian hold similar, relatively tolerant and forgiving attitudes. The divergence from Feldman and Stenner comes from two assumptions: first, that the more authoritarian nearly constantly feel threatened; second, that the less authoritarian will respond to perceived threat in the same way authoritarians do. Hetherington

\footnotetext{
${ }^{1}$ Though Hetherington and Weiler refer to authoritarianism as a disposition, they characterize it as a predisposition: authoritarians do not have an intolerant disposition per se, they are however more susceptible to intolerance due their heightened sensitivity to threat.
} 
and Weiler argue that the real world is "generally a threatening place for those scoring high in authoritarianism" (2009, p. 117). Perception of threat is therefore likely to be the status quo for the more authoritarian; in other words, the more authoritarian always feel more threatened and will therefore always be disposed toward the expression of more intolerant and punitive attitudes. The less authoritarian, on the other hand, are less susceptible to threat. Yet, when they do feel threatened, they also become more intolerant and punitive. Essentially, then, Hetherington and Weiler (2009) boil authoritarianism down to threat susceptibility, with those across the authoritarianism scale responding in identical fashion to threat but differing in their susceptibility to such.

Much of the current research on authoritarianism focuses on intolerance and punitiveness and tells us very little about beliefs about democracy per se. However, if we take tolerance, or at least the acceptance of societal pluralism, to be a fundamental component of liberal-democracy (cf., Sartori, 1997), given the above conceptualization of authoritarianism, we can draw certain expectations about what those across the authoritarianism-libertarianism continuum believe democracy should entail.

The more authoritarian, who are more likely to perceive a continual threat to the social unity and uniformity of their ingroup (Hetherington \& Weiler, 2009), are unlikely to believe in a liberal form of democracy as liberal-democracy is intended to promote and protect diversity and dissent (Markoff, 2011; Sartori, 1997). The less authoritarian, or the more libertarian (Stenner, 2005), those who prefer individual autonomy to social conformity, are more likely to hold liberal beliefs about democracy as these align with their preference for individual autonomy. Authoritarianism, then, will be negatively correlated with the belief that democracy should necessitate liberal characteristics. 
This relationship, however, may be dependent on political context. Dunn (2014) finds that individual tolerance is correlated with a country's level of liberal-democracy and this applies to both the more and less authoritarian. However, the difference in tolerance levels between the more and less authoritarian is greater in more liberal democracies. As those in more liberaldemocracies are more likely to express tolerance toward ethnic and social minorities than those in less liberal-democratic countries (Dunn, 2014), one could also reason that they are more likely to support liberal beliefs about democracy in more liberal democracies for the same reason: liberal norms are the norms of their society. Similarly, as this increase in liberal-democratic societal norms increases, it diverges from the inherent preferences of the more authoritarian and may thereby be embraced to a lesser degree than it will be by the more libertarian, who prefer more liberal outcomes due to their preference for individual autonomy.

While the more authoritarian in more liberal democracies may have stronger liberal beliefs about democracy, this does not require them to be content with the consequences of this belief. For those who prefer unity and uniformity to dissent and diversity, the belief that democracy is an inherently liberal form of governance that promotes the expression of dissent and diversity at the expense of the unity and uniformity of the ingroup may taint attitudes toward democracy itself. In other words, the more authoritarian may have a more negative, or at least a less positive, attitude toward democracy if they believe that democracy is an inherently liberal form of regime. 


\section{Hypotheses}

Based on the above discussion, I derive the following hypotheses²:

$\mathrm{H}_{1}$ : The more libertarian will more strongly associate democracy with liberal characteristics than will the more authoritarian.

$\mathrm{H}_{2}$ : The difference in liberal beliefs about democracy between the more authoritarian and the more libertarian will be greater in more liberal-democratic countries; i.e., there should be a positive interaction between authoritarianism and level of liberal-democracy

$\mathrm{H}_{3 \mathrm{a}}$ : Liberal beliefs about democracy will predict a more positive attitude toward democracy as a form of governance among the more libertarian.

$\mathrm{H}_{3 \mathrm{~b}}$ : Liberal beliefs about democracy will predict a less positive attitude toward democracy as a form of governance among the more authoritarian.

$\mathrm{H}_{3 \mathrm{a}}$ in conjunction with $\mathrm{H}_{3 \mathrm{~b}}$ predicts a positive interaction between authoritarianism and liberal beliefs about democracy.

\footnotetext{
${ }^{2}$ In the following hypotheses I assume, following Hetherington and Weiler (2009), that on average the status quo state of authoritarians is to feel threatened while the status quo state of libertarians is to not feel threatened.
} 


\section{Method}

\section{Sample}

To test the above hypotheses I rely on three data sources: the $6^{\text {th }}$ wave of the World Values Survey ${ }^{3}$ (WVS $_{6}$ ), the Freedom House Freedom in the World country ratings ${ }^{4}$, and the World Bank's Worldwide Governance Indicators data (WGI). ${ }^{5}$

The individual-level data in the analyses relies solely on the $\mathrm{WVS}_{6}$. The WVS draws a representative sample of at least 1000 respondents between the ages of 18 and 85 for each country involved in the study. Either full probability sampling or strictly governed quota sampling is conducted depending on available resources. Interviews are conducted face-to-face. The $\mathrm{WVS}_{6}$ surveys individuals from 60 countries from around the globe over the course of four years, from 2010 to 2014. Missing data reduces the sample used here to 58 countries and 76,074 individuals.

\section{Measures}

Liberal Beliefs about Democracy: The dependent variable in the following analyses is derived from responses to two questions from the $\mathrm{WVS}_{6}$. Each of these questions follow on from the following statement:

Many things may be desirable, but not all of them are essential characteristics of democracy. Please tell me for each of the following things how essential you think it is as a characteristic of democracy. Use this scale where 1 means "not

\footnotetext{
${ }^{3}$ Data can be found at: http://www.worldvaluessurvey.org

${ }^{4}$ Data can be found at: https://freedomhouse.org

${ }^{5}$ Data can be found at: http://info.worldbank.org/governance/wgi/\#home
} 
at all an essential characteristic of democracy" and 10 means it definitely is "an essential characteristic of democracy".

Liberal beliefs about democracy focus on the necessity for liberal characteristics and is the average score of individuals' responses to "Civil rights protect people's liberty against oppression" and "Women have the same rights as men". These two variables are averaged to provide the liberal beliefs about democracy scale. This variable is rescaled to range from 0 to 1 , with higher scores indicating a stronger belief that democracy entails a baseline of protection again oppression and discrimination.

Attitude toward Democratic Governance: The secondary dependent variable in the following analyses, one's attitudes toward democratic governance, is derived from a question that asks respondents, on a scale of 1 to 10 , "how important is it for you to live in a country that is governed democratically?" This variable is rescaled to range from 0 to 1 with a higher value indicative of a more positive attitude towards democratic governance.

Libertarianism-Authoritarianism: As previously noted, I follow Stenner (2009, p. 142) in defining authoritarianism as an individual predisposition concerned with "the appropriate balance between group authority and uniformity and individual autonomy and diversity." Following Dunn, Spaiser, and Dodds (2020), and similar to Dunn, Griffiths, Lamb, Shortt, and Theochari (2017) and Arikan and Sekercioglu (2019), I adopt Feldman's (2003) SCA-V (social conformity autonomy values) approach to measuring authoritarianism. Using the Schwartz (2012) 10-item values inventory included in the $\mathrm{WVS}_{6}$, I average each individual's scores on the stimulation and self-direction values items to produce the Individual Autonomy Values scale. I do the same for the conformity and tradition values items to produce the Social Conformity Values scale. Each scale 
ranges from 1 to 6 with a higher score indicating a higher reported identification with that value cluster. I then subtract the Individual Autonomy Values scale from the Social Conformity Values scale. This produces an authoritarianism scale ranging from -5 to +5 . Those who score below 0 , the midpoint of the scale, prioritize individual autonomy over social conformity, while those who score above 0 prioritize social conformity over individual autonomy. Those who score precisely 0 prioritize neither. Higher scores on this scale indicate a greater degree of authoritarianism, while lower scores indicate a greater degree of libertarianism. Previous analyses of this scale indicate that this scale is configurally invariant across 54 countries (Dunn et al., 2020).

Effective Democracy: Hypothesis $\mathrm{H}_{2}$ proposes that the relationship between authoritarianism and liberal beliefs about democracy is conditional on the level of liberaldemocracy in a country. For this reason, it is necessary to have a measure of liberal-democracy. Following previous cross-national research in the authoritarianism literature (Dunn, 2014; Dunn \& Singh, 2014), I utilize the concept of effective democracy (e.g., Welzel, Inglehart, \& Klingemann, 2003). In essence, the effective democracy index measures the effective delivery of institutionalized liberal-democratic freedoms in a country (Alexander, Inglehart, \& Welzel, 2012).

Following the measurement strategy of Alexander and Welzel (2011), the measure of effective democracy used in the following analyses is a multiplicative combination of the averaged Freedom House scores for "civil liberties" and "political rights", which account for the institutionalization of liberal-democratic principles, and the averaged World Bank's Worldwide Governance Indicators" “control of corruption" and "rule of law” scores (cf., Kaufmann, Kraay, \& Mastruzzi, 2011), which account for the effective delivery of institutionalized principles. For each country the values of the component measures of effective democracy correspond to the year in which the survey began. To construct the effective democracy measure, first, the civil liberties and 
political rights measures are inverted, so that higher scores indicate greater institutionalization of liberal-democratic principles, summed, and rescaled to range from 0 to 1 . The control of corruption and rule of law measures are also averaged and then rescaled to range from 0 to 1 . These two measures are then multiplied to create the effective democracy measure which ranges from 0 to 1 with a higher score indicating a higher level of effective democracy. As one can see from Figure 2, the countries line up as one might expect with China and Russia scoring toward the bottom of the scale, Singapore and South Korea scoring near the middle of the scale, and Sweden and New Zealand scoring at the top.

Consistent with the idea that current levels of liberal-democracy correlate with beliefs about democracy, those countries that score higher on this effective democracy measure also exhibit a stronger average belief that democracy necessitates liberal characteristics $(r=0.549, p<$ $0.001)$.

Control Variables: The following analyses control for basic demographics: age, education, gender, and income. Age is a measure of the respondent's reported age rescaled to range from 0 to 67. Education is a variable derived from a question inquiring in to the respondent's highest level of education; ranging from 0 (no formal education) to 6 (university-level education, with degree). Gender is coded by the interviewer as male or female based on his/her observation of the respondent. Male is coded as 0 ; female as 1 . Income is a measure of respondent's income level in terms of country-specific income measurements; ranging from 0 to 9 , with higher values indicating a higher level of income. 


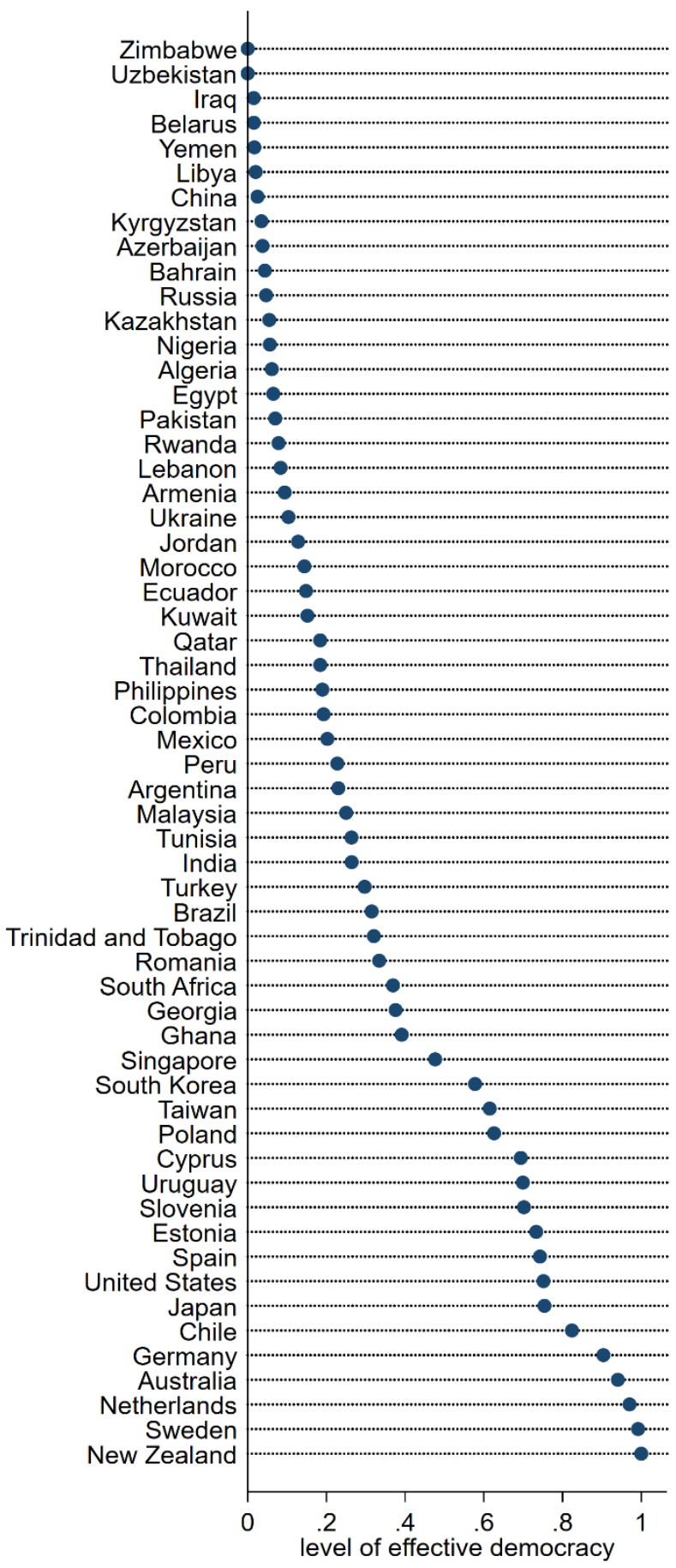

Figure 1: The effective democracy score for each country in the dataset. 


\section{Results}

The following analyses use multi-level, random effects models for two reasons: first, multilevel models allow for the non-independence of within country observations. An intercept only model of the liberal beliefs scale, indicates that $10.3 \%$ of the variance in this variable is attributable to country-level factors. An intercept only model of the attitude toward democracy variable indicates that $5 \%$ of the variance is due to country-level factors. Both models indicate that within country observations are not independent of one another; analyses therefore require a multilevel framework. Second, multi-level models allow one to simultaneously examine both individual-level and country-level variables, and even allow for the interaction of such, without falsely inflating the significance of country-level variables. As $\mathrm{H}_{2}$ requires an interaction between an individualand country-level variable, a multi-level model is required. A random effects specification allows for the possibility that any variation in slopes between countries is 'true' variation. A random effects specification indicates that I am estimating an average slope among varying 'true' slopes.

Table 1: linear mixed model of liberal beliefs about democracy

Model 1

\begin{tabular}{lcccccc} 
& $\beta$ & s.e. & p-value & $\beta$ & s.e. & p-value \\
\hline & & & & & & \\
authoritarianism & 0.012 & 0.001 & 0.000 & 0.019 & 0.001 & 0.000 \\
effective democracy & 0.127 & 0.023 & 0.000 & 0.137 & 0.023 & 0.000 \\
& & & & & & \\
authoritarianism * democracy & -- & -- & -- & -0.021 & 0.002 & 0.000 \\
& & & & & & \\
age & 0.000 & 0.000 & 0.000 & 0.000 & 0.000 & 0.000 \\
education & 0.013 & 0.001 & 0.000 & 0.013 & 0.001 & 0.000 \\
gender (female) & 0.011 & 0.002 & 0.000 & 0.012 & 0.002 & 0.000 \\
income & 0.000 & 0.000 & 0.716 & 0.000 & 0.000 & 0.974 \\
constant & & & & & & \\
& 0.631 & 0.011 & 0.000 & 0.625 & 0.011 & 0.000 \\
\hline
\end{tabular}


Table 1 reports the output from two multi-level models predicting liberal beliefs about democracy. Model 1 of Table 1 reports the output of an additive, non-interactive model. This model indicates that authoritarianism is positively associated with liberal beliefs about democracy.

\begin{tabular}{|c|c|c|c|}
\hline \multicolumn{4}{|c|}{$\begin{array}{l}\text { Table 2: the coefficient on } \\
\text { authoritarianism as effective democracy } \\
\text { changes }\end{array}$} \\
\hline $\begin{array}{c}\text { effective } \\
\text { democracy }\end{array}$ & $\beta$ & s.e. & $\mathrm{p}$-value \\
\hline 0 & 0.019 & 0.001 & 0.000 \\
\hline 0.1 & 0.017 & 0.001 & 0.000 \\
\hline 0.2 & 0.015 & 0.001 & 0.000 \\
\hline 0.3 & 0.013 & 0.001 & 0.000 \\
\hline 0.4 & 0.010 & 0.001 & 0.000 \\
\hline 0.5 & 0.008 & 0.001 & 0.000 \\
\hline 0.6 & 0.006 & 0.001 & 0.000 \\
\hline 0.7 & 0.004 & 0.001 & 0.000 \\
\hline 0.8 & 0.002 & 0.001 & 0.078 \\
\hline 0.9 & 0.000 & 0.001 & 0.831 \\
\hline 1 & -0.002 & 0.001 & 0.084 \\
\hline
\end{tabular}

Model 2 in Table 1 indicates that the relationship between authoritarianism and liberal beliefs is conditional on a country's level of effective democracy. To simplify interpretation of the interaction, Table 2 lists the coefficient on authoritarianism over the range of the effective democracy variable for both of the dependent variables. For example, in Model 2 of Table 1, the coefficient on authoritarianism is 0.020 . This corresponds to value of authoritarianism when effective democracy equals 0 (cf., Braumoeller, 2004). In Table 2, the coefficient on authoritarianism at effective democracy $=0$ is 0.020 . Proceeding down the list, as the value of effective democracy increases, the coefficient on authoritarianism decreases to the point of insignificance in the more effective democracies. For the most part, authoritarians report more 
liberal beliefs about democracy than do libertarians; however, in the most effective democracies, one's authoritarian predisposition does not predict any difference in liberal beliefs about democracy.

\section{Dependent Variable: Liberal Beliefs}

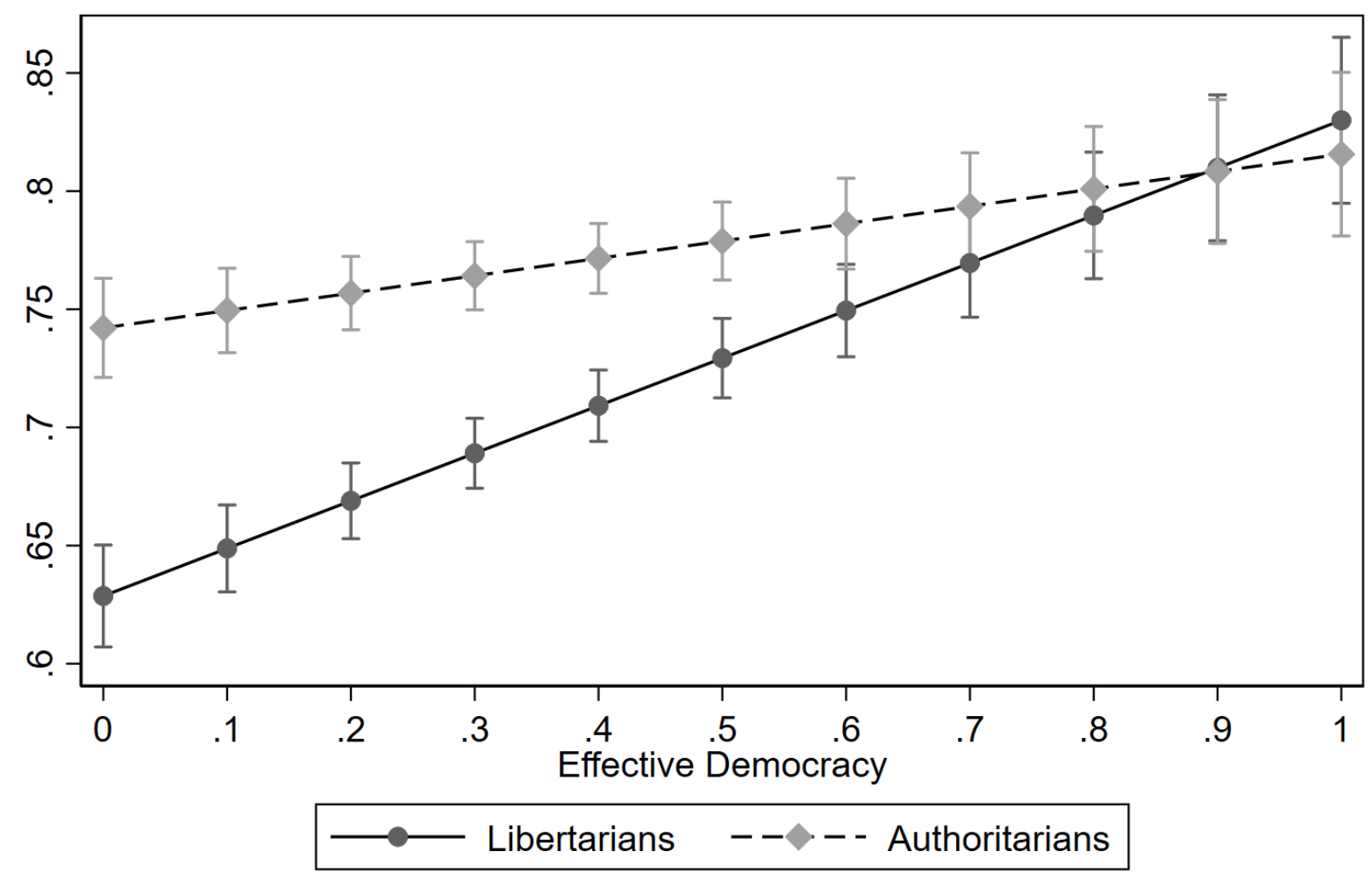

Figure 2: Predicted values of the strength of association of liberal characteristics with democracy for those who score at \pm 3 on the authoritarianism scale across the range of effective democracy.

This relationship is illustrated in Figure 3. In this graph, I plot the predicted values on the liberal beliefs variable for those at +3 on the authoritarianism scale (labelled authoritarians) and those at -3 on the authoritarianism scale (labelled libertarians). Reflecting the previous discussion, the figure illustrates that as effective democracy increases, the initially large gap between 
authoritarians and libertarians decreases to the point of insignificance. This graph provides a more nuanced understanding of the relationship. First, the figure reveals that both authoritarians and libertarians hold more liberal beliefs about democracy in more effective democracies. Second, while we can see that there is certainly a difference in the beliefs of authoritarians across effective democracy, libertarians seem to be the main driver of this conditional relationship. The slope for the authoritarian line is 0.074 (s.e. $=0.024, \mathrm{p}=0.002$ ) while the slope for the libertarian line is 0.201 (s.e. $=0.024, p<0.001$ ). As effective democracy increases, so too does the strength of the more libertarians' belief in how essential liberal characteristics are to democracy; increasing to the point where they rival the rather strong beliefs of authoritarians.

These findings for liberal beliefs about democracy are counter to what is set out in the first two hypotheses. $\mathrm{H}_{1}$, which states that the more libertarian will more strongly believe that liberal characteristics are necessary for democracy than will the more authoritarian is not supported. As noted in Table 2, the relationship, where significant, is actually the opposite of that expected: authoritarianism is positively correlated with liberal beliefs about democracy. $\mathrm{H}_{2}$, which suggests a positive interaction between authoritarianism and effective democracy is also the opposite of what is found here: there is a negative interaction between authoritarianism and effective democracy. As shown in Table 2 and illustrated in Figure 2, the gap between the beliefs of the more authoritarian and the more libertarian decreases as effective democracy increases.

To investigate whether either this relationship is due to negative attitudes toward liberal beliefs about democracy, in Table 3 I report an analysis of an interactive model, conditioning liberal beliefs about democracy on authoritarianism, predicting attitudes toward democratic governance. The combination of hypotheses $\mathrm{H} 3 \mathrm{a}$ and $\mathrm{H} 3 \mathrm{~b}$ suggest a positive interaction between authoritarianism and liberal beliefs where attitudes toward democracy among the more 
authoritarian will be lower where liberal beliefs are higher and where attitudes toward democracy among the more libertarian will be higher where liberal beliefs are higher.

\begin{tabular}{lccc}
\hline \hline $\begin{array}{l}\text { Table 3: linear mixed model of attitudes toward } \\
\text { democracy }\end{array}$ & & & \\
\hline & $\beta$ & s.e. & p-value \\
\hline & 0.018 & 0.002 & 0.000 \\
$\begin{array}{l}\text { authoritarianism } \\
\text { liberal beliefs }\end{array}$ & 0.286 & 0.004 & 0.000 \\
& & & \\
authoritarianism * liberal & -0.014 & 0.002 & 0.000 \\
& & & \\
age & 0.001 & 0.000 & 0.000 \\
education & 0.011 & 0.001 & 0.000 \\
gender (female) & -0.007 & 0.002 & 0.000 \\
income & 0.003 & 0.000 & 0.000 \\
& & & \\
effective democracy & 0.041 & 0.015 & 0.007 \\
& & & \\
constant & 0.524 & 0.008 & 0.000 \\
\hline
\end{tabular}

As with $\mathrm{H} 1$ and $\mathrm{H} 2$, this is not borne out in the analyses. Table 3 indicates a negative, rather than a positive, interaction indicating a narrowing gap between the attitudes of the more libertarian and the more authoritarian. This is reinforced by Table 4 which reports the coefficient on authoritarianism across the range of liberal beliefs about democracy. Authoritarianism predicts less variation in attitude toward democracy as liberal beliefs about democracy increase in strength. Further, as illustrated in Figure 3, where liberal beliefs about democracy are stronger attitude 
toward democracy is more positive, even controlling for effective democracy. ${ }^{6}$ While this is certainly not conclusive evidence that the more authoritarian do not hold negative views of their liberal beliefs about democracy, it does suggest such.

\begin{tabular}{|c|c|c|c|}
\hline $\begin{array}{l}\text { liberal } \\
\text { beliefs }\end{array}$ & $\beta$ & s.e. & p-value \\
\hline 0 & 0.018 & 0.002 & 0.000 \\
\hline 0.1 & 0.016 & 0.001 & 0.000 \\
\hline 0.2 & 0.015 & 0.001 & 0.000 \\
\hline 0.3 & 0.013 & 0.001 & 0.000 \\
\hline 0.4 & 0.012 & 0.001 & 0.000 \\
\hline 0.5 & 0.011 & 0.001 & 0.000 \\
\hline 0.6 & 0.009 & 0.001 & 0.000 \\
\hline 0.7 & 0.008 & 0.001 & 0.000 \\
\hline 0.8 & 0.006 & 0.001 & 0.000 \\
\hline 0.9 & 0.005 & 0.001 & 0.000 \\
\hline 1 & 0.004 & 0.001 & 0.000 \\
\hline
\end{tabular}

\section{Discussion}

Initial discussions of authoritarianism were an attempt to uncover why democratic citizens would not only permit, but in some cases facilitate the overthrow of democratic regimes (e.g., Adorno et al., 1950; Fromm, 1941; Lipset, 1959). It is not surprising then that authoritarianism as a personal characteristic or personality type was also referred to as a fascistic or anti-democratic personality (cf., Frenkel-Brunswik, Levinson, \& Sanford, 1947). The characterization of

\footnotetext{
${ }^{6} \mathrm{~A}$ model that includes a three-way interaction between authoritarianism, liberal beliefs, and effective democracy does report a significant three-way interaction, but does not change the general conclusions that follow. The difference in the authoritarianism / liberal beliefs interaction across the range of effective democracy is minor.
} 
authoritarians as enemies of freedom (Altemeyer, 1988) seems appropriate given its origins and associated characteristics. More recent research that focuses particularly on authoritarians' predisposition toward intolerance and punitiveness only serves to further the supposition that authoritarians cannot possibly be supportive of liberal democracy; after all, liberal democracy, as a form of regime designed to protect diversity and dissent (e.g., Markoff, 2011; Sartori, 1997), is antithetical to the unity and uniformity authoritarians prioritize (Dunn, 2014; Dunn \& Singh, 2014).

\section{Dependent Variable: Attitude Toward Democracy}

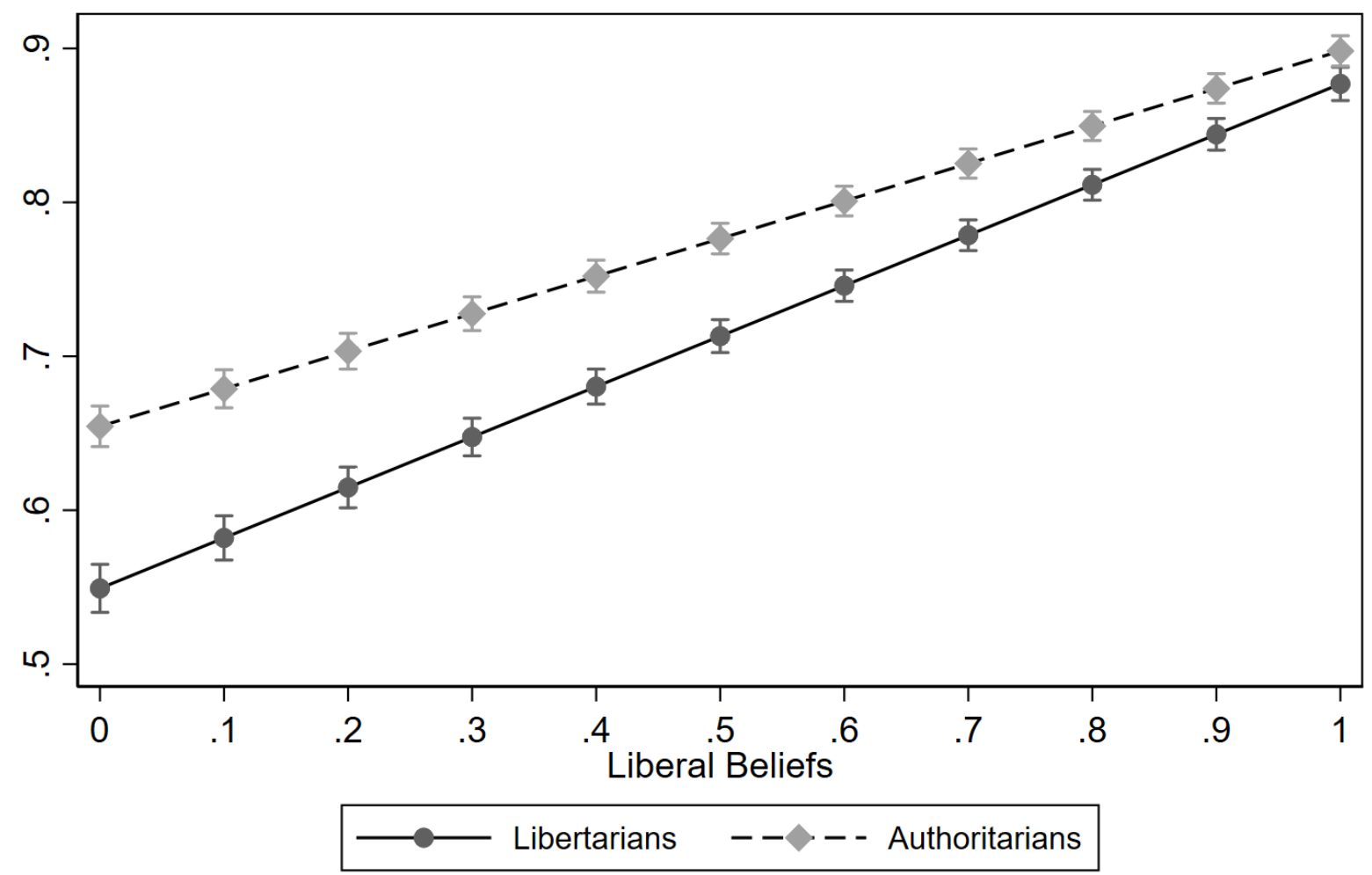

Figure 3: Predicted values of attitudes toward democracy for those who score at \pm 3 on the authoritarianism scale across the range of liberal beliefs. 
Though a great deal of recent research has delved into the (increasingly nuanced) relationship between authoritarianism and intolerant and punitive attitudes, the early concern regarding beliefs about and support for democracy have largely faded over time. Using data from 58 countries from around the globe, this article begins to fill this absence in the literature. Looking at a wide variety of countries allows me to examine not just whether the beliefs about democracy we expect to find in the West actually exist, but also whether these expectations are universal or conditional on political context.

The analyses in this article focus on liberal beliefs about democracy. Drawing on previous literature, I hypothesized that the relationship between authoritarianism and liberal beliefs would be largely negative, with the more authoritarian generally less supportive of liberal beliefs than the more libertarian. It was also my expectation that while those on both sides of the scale would hold stronger liberal beliefs about democracy, the negative relationship between authoritarianism and liberal beliefs would be more substantial in more liberal democratic countries. The only aspect of these hypotheses that was supported: stronger liberal beliefs about democracy are held among both the more and less authoritarian in more liberal democracies.

Contrary to expectations, in the least effective democracies, the relationship between authoritarianism and liberal beliefs about democracy is positive; that is, in less liberal-democratic societies it is the more authoritarian, rather than the more libertarian, who hold stronger beliefs that liberal characteristics are essential to democracy. Further while the relationship between authoritarianism and strength of liberal beliefs about democracy is conditional on the level of liberal democracy in a country, the substantive relationship between authoritarianism and liberal beliefs declines. Whereas in the least liberal democracies there is a substantive positive relationship between authoritarianism and liberal beliefs, this decreases to the point of 
insignificance in the more liberal democracies. One caveat to these findings is that strength of liberal beliefs about democracy is always predicted to be above the midpoint of the scale; regardless of level of authoritarianism or level of liberal democracy, liberal beliefs are always considered more essential to democracy than not.

These findings upend expectations that I derive from the literature regarding the beliefs that the more or less authoritarian will hold about democracy. The evidence found throughout the literature that the more authoritarian are rather intolerant and punitive does not mesh well with the pluralism that underlies liberal-democracy, yet the results herein show that authoritarians do indeed associate democracy with liberal characteristics. One potential explanation for these findings is that while the democracy-beliefs inventory used in this research does allow us to look at (a constrained image of) what respondents believe about democracy, it does not allow us to understand people's attitudes toward those beliefs. For example, while many Western academics likely possess a positive attitude toward those liberal characteristics associated with democracy, it is entirely possible that some people, especially authoritarians in non-democracies, may view such traits as a damning indictment of democracy. One needs to look only as far as extreme- and radicalright party elites and supporters in many Western democracies to see that liberal-democracy is hardly a universally accepted ideology (cf., Ignazi, 1992, 2003). It may be that while the more authoritarian under non-democratic regimes do associate liberal characteristics with democracy, such an association may be quite negative and reflect poorly on attitudes toward democracy.

While the WVS data does not allow me to directly determine whether these beliefs are tied to positive or negative attitudes, I was able to examine whether those who believe liberal characteristics are essential to democracy are more or less supportive of democracy in general. This at least allows me to examine whether a stronger or weaker belief that these liberal 
characteristics are necessary for democracy is predictive of stronger or weaker support for democracy. This, in turn, provides indirect evidence of individuals' attitudes toward the associated characteristics.

Once again, though, the results of my analysis that regresses a respondent's attitude toward democratic governance on the interaction between authoritarianism and the strength of liberal beliefs about democracy fails to support the idea that authoritarians with stronger liberal beliefs hold a more negative view of democratic governance; as liberal beliefs about democracy strengthen, so too does support for democratic governance among both the more and less authoritarian. Though this is not conclusive evidence, it does suggest that both authoritarians and libertarians generally hold a more positive attitude toward democracy when they more strongly believe that liberal characteristics are essential to democracy.

Accepting, then, that the more authoritarian's attitudes toward liberal characterizations of democracy are positive, there are still two further issues that need clarifying before we can truly understand how authoritarianism relates to beliefs about and support for democracy. First, we must consider the potential divergence between abstract beliefs and more concrete social and political attitudes. Previous research shows a clear disparity between abstract beliefs and concrete policy preferences (McClosky, 1964; Prothro \& Grigg, 1960) and given the intolerance and punitiveness often expressed by the more authoritarian, it seems probable that there may be at least a moderate disconnect between beliefs in the more liberal aspects of democracy and support for the concrete results of such.

Second, previous research (Altemeyer, 1996; Duckitt, 1989) suggests the possibility that the more authoritarian may be something akin to democracy-chauvinists: only we get to benefit 
from our liberal democratic guarantees; our guarantees do not apply to them. In other words, the status-quo us-them orientation of the more authoritarian may lead authoritarians to hold rather liberal abstract views of democracy but only wish to apply them to those who do not threaten the unity and uniformity of the ingroup.

It is also possible that previous characterizations of authoritarians as anti-democrats are based solely on previous formulations and measurements of the concept. Some of the more traditional characterizations may not fit this values-based conceptualization of authoritarianism. 


\section{References}

Adorno, T. W., Frenkel-Brunswik, E., Levinson, D. J., \& Sanford, R. N. (1950). The authoritarian personality (1st ed.). New York: Harper.

Alexander, A. C., Inglehart, R., \& Welzel, C. (2012). Measuring Effective Democracy: A defense. International Political Science Review, 33(1), 41-62.

Alexander, A. C., \& Welzel, C. (2011). Measuring Effective Democracy: The Human Empowerment Approach. Comparative Politics, 43(3), 271-289.

Altemeyer, B. (1988). Enemies of Freedom: Understanding right-wing authoritarianism (1st ed.). San Francisco: Jossey-Bass Publishers.

Altemeyer, B. (1996). The authoritarian specter. Cambridge, MA: Harvard University Press.

Arikan, G., \& Sekercioglu, E. (2019). Authoritarian Predispositions and Attitudes Towards Redistribution. Political Psychology, 40(5), 1099-1118.

Braumoeller, B. F. (2004). Hypothesis Testing and Multiplicative Interaction Terms. International Organization, 58(04), 807-820.

Duckitt, J. (1989). Authoritarianism and group identification: A new view of an old construct. Political Psychology, 10(1), 63-84.

Dunn, K. (2014). Authoritarianism and Intolerance Under Autocratic and Democratic Regimes. Journal of Social and Political Psychology, 2(1), 220-241.

Dunn, K., Griffiths, E., Lamb, S., Shortt, R., \& Theochari, E. (2017). The Human Empowerment Sequence and the Development of Libertarian Values: A Theoretical and Empirical Adjustment to the Human Empowerment Sequence. Journal of Cross-Cultural Psychology, 48(5), 771-789. 
Dunn, K., \& Singh, S. P. (2014). Pluralistic Conditioning: Social tolerance and effective democracy. Democratization, 21(1), 1-28.

Dunn, K., Spaiser, V., \& Dodds, H. J. (2020). The Role of Threat in the Human Empowerment Sequence. https://doi.org/10.31234/osf.io/3zun4.

Feldman, S. (2003). Enforcing social conformity: A theory of authoritarianism. Political Psychology, 24(1), 41-74.

Feldman, S., \& Stenner, K. (1997). Perceived threat and authoritarianism. Political Psychology, $18(4), 741-770$.

Frenkel-Brunswik, E., Levinson, D. J., \& Sanford, R. N. (1947). The Antidemocratic Personality. In E. E. Maccoby, T. M. Newcomb \& E. L. Hartley (Eds.), Readings in Social Psychology. New York: Henry Holt \& Co.

Fromm, E. (1941). Escape from freedom. New York: Farrar \& Rinehart.

Hetherington, M. J., \& Suhay, E. (2011). Authoritarianism, threat, and Americans' support for the War on Terror. American Journal of Political Science, 55(3), 546-560.

Hetherington, M. J., \& Weiler, J. D. (2009). Authoritarianism and Polarization in American Politics. Cambridge; New York: Cambridge University Press.

Ignazi, P. (1992). The silent counter-revolution. European Journal of Political Research, 22(1), 334.

Ignazi, P. (2003). Extreme Right Parties in Western Europe. Oxford: Oxford University Press.

Kaufmann, D., Kraay, A., \& Mastruzzi, M. (2011). The Worldwide Governance Indicators: Methodology and Analytical Issues. Hague Journal on the Rule of Law, 3(2), 220-246.

Lipset, S. M. (1959). Democracy and Working-Class Authoritarianism. American Sociological Review, 24(4), 482-501. 
Lipset, S. M. (1960). Political Man: The social bases of politics. Garden City, N.Y.: Doubleday. Markoff, J. (2011). A moving target: Democracy. European Journal of Sociology, 52(02), 239276.

McClosky, H. (1964). Consensus and ideology in American politics. The American Political Science Review, 58(2), 361-382.

Prothro, J. W., \& Grigg, C. M. (1960). Fundamental principles of democracy: Bases of agreement and disagreement. The Journal of Politics, 22(2), 276-294.

Sartori, G. (1997). Understanding pluralism. Journal of Democracy, 8(4), 58-69.

Stenner, K. (2005). The Authoritarian Dynamic. New York, NY: Cambridge University Press.

Stenner, K. (2009). Three kinds of “conservatism”. Psychological Inquiry, 20(2-3), 142-159.

Welzel, C., Inglehart, R., \& Klingemann, H.-D. (2003). The Theory of Human Development: A cross-cultural analysis. European Journal of Political Research, 42(3), 341-379. 